INTERNATIONAL DESIGN CONFERENCE - DESIGN 2018

https://doi.org/10.21278/idc.2018.0480

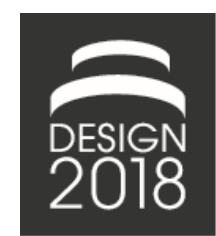

\title{
ON KNOWLEDGE MATURITY AND BIASED NATURE OF STAGED DECISION MAKING IN A HIGH CONSEQUENCE INDUSTRY
}

\author{
M. Svensson, A. Bertoni and M. Lanander
}

\begin{abstract}
This paper explores and problematizes decision-making in a high-consequence industry which is characterized by the stage-gate process. We showcase that decision-makers do not differentiate between the types of knowledge used for modelling decisions and calculation of risks. This makes them susceptible to incorporating cognitive distortions - biases - into the stage-gate process. We conclude by amending the risk for certain kinds of biases with a knowledge maturity framework in order to outline conditions for pragmatic decision making.
\end{abstract}

Keywords: decision making, uncertainty, knowledge maturity, risk management, decision biases

\section{Introduction}

A high-consequence risk industry is an industry wherein risks may lead to drastic consequences, such that would impact human health or safety. Within these industries, managing potentially dangerous scenarios means putting a large emphasis on decision making (Zio and Pedroni, 2013). In a product development context, a Stage-Gate process (Cooper, 2008) has been commonly adopted to control and manage the decision process and facilitate rational decision making (Engwall et al., 2005). When dealing with high-risk new technology development the Stage-Gate process has been found critical to ensure the allocation of resources and the reduction of the overall cycle time (Ajamian and Koen, 2002). The process involves stages, from preliminary design to final product, and every stage ends with a gate wherein an evaluation is done and decisions are made. As a product or service is designed over time, the knowledge about the design problem increases while the freedom to make changes decreases commonly known as the design paradox (Ullman, 2003). Making decisions in this setting favours normative estimations of probability distributions in order to get a better understanding of the likelihood of outcomes (Smidts, 1990). However, in uncertain and ambiguous situations, the objectivity of observed variables may be questioned or considerably difficult to obtain, given the absence of viable mental models, i.e. the absence of appropriate mental representation of the situation.

In industries where design evaluations involve high-consequence risks, it is not only imperative, but also a necessity to define facts and their relationships in mental models and thereby decrease uncertainty (Zio and Pedroni, 2013) in order to improve the effectiveness of decision making and coming closer to a functional and safe product. A lack of information means that decisions are based on a partial understanding of the environment, thus normative decisions based on perfect accuracy and full rationality cannot be applied (Ellsberg, 1961). Therefore decision-makers are sometimes forced to supplement knowledge by applying subjective decision weights based on experience and intuition (Boading, 2012; Zio and Pedroni, 2013). Consequently, such situations are affected by human cognitive 
shortcomings and biased thinking. Here uncertainty is traditionally defined as a void of information where no clear understanding can be discerned (Ellsberg, 1961; Raftery, 1996), but there is also the need to clearly differentiate such concept of uncertainty from the presence ambiguous conditions, consisting instead in the inadequacy of mental models in describing the problem space (Schrader et al., 2010) making it more difficult to find viable parameters to assess.

Failing to differentiate between types of information, or to find adequate models of the problem space, may lead either to neglect of important information or to wrongfully applying estimates, causing problems to arise in decision making (e.g. Kahneman et al., 1991; Mussweiler et al., 2004). Such issues, highlight the need to improve understanding of the information that is needed as well as which types of biases that could be presented (Zio and Pedroni, 2013) in gated decision-making processes.

Engineering design literature proposes Knowledge Maturity (KM) (Johansson et al., 2011) to deal with uncertainty in the stage gate process. The KM concept assumes that the better the source of the information provided the more appropriately it is handled, the more certain and mature the information is. Part of its intention is to elucidate uncertainties by a clear understanding of boundary conditions. However, while this type of assessment serves to provide guidelines for boundary conditions, it does not typically address the type of information needed, nor the biases that may emerge in a development process.

This paper aims to explore and problematize foundations for the use of knowledge maturity assessment in high-consequence industries. Knowledge Maturity (Johansson et al., 2011) supports evaluation in cases of uncertainty and the knowledge maturity scale is a method perpetrating this in a stage-gate process. However, there are no defined means of specifically managing types of information (uncertainties or ambiguities) in the scale. The following section describes the objective of the paper, and the limitations in the sample of data collection consisting of a single case company analysis operating in the aerospace industry. Section 3 presents the theoretical framework of reference of the paper. Section 4 describes the research approach and the method used for data collection and analysis. Section 5 describes the results of the empirical study and Section 6 discusses the findings in relation to decision-making theory. Section 7 concludes the study.

\section{Objectives and delimitation}

The research builds on concepts from decision making literature and of Knowledge Maturity (Johansson et al., 2011) and aims to further amend the knowledge maturity scale accounting for assessments of various types of information that needs to be considered in the assessment. In order to achieve such objective, the following research question was investigated:

- How do engineers in a high-consequence risk view uncertainty and ambiguity in engineering design decision making?

The scope of the study is limited to engineering design within a high-consequence risk industry that apply the stage-gate processes. These areas include early design stages facing a prominent design paradox (Ullman, 2003). The collection of the empirical data concerned interviews at a single case company and thereby serves to exemplify and problematize different cognitive shortcomings in the decision-making process, without exhaustive claims of empirical generalizability to other stage-gated developmental processes.

\section{Theoretical framework}

\subsection{Constituents of decision making}

Decision theory can meaningfully be separated in the forms of normative and descriptive decision theory. Normative decision theories regard those that dictate the rational behaviour when faced with risk. It concerns the consistency in decisions given someone's preferences in relation to exogenous signals. Thus, they describe how optimal decisions should be made (Tversky and Kahnman, 1986; Bell et al., 1988). For instance, in a choice between design elements, if I prefer one element (A) over another (B), which in turn is preferred over another (C) I should prefer A over $\mathrm{C}$ as a rational consequence. On the contrary, descriptive decision theories are aligned with how decisions actually are made based on 
people's inability to obtain full information and given their cognitive constraints, thereby causing them to deviate normative standards. Thus, the latter considers how a decision is made rather than why it should be made in a certain way, and accounts for what is seemingly irrational and biased behaviour (Hansson, 2005). Something that often differs from what is assumed to be rational normative decision making has been shown by studies of descriptive decision making to directly work in opposition to the normative decision theories (Tversky and Kahnman, 1986; Bell et al., 1988). Consequently, a designer may be inconsistent choosing B over C and A even though A was preferred initially. Descriptive theories therefore regard "bounded rationality, whereby choice behaviour is regulated by cognitive and environmental constraints" (Rakow, 2010, p. 458) and has therefore been argued to better describe decision making (Alexander, 1975). The behaviour surrounding choice is dominated by cognitive constraints and the environment of the choice itself, meaning that engineers do not base their decision solely on the probable outcomes of utilities (Kahneman and Tversky, 1979). However, a downside of the descriptive approach is that individuals are prone to make a number of non-rational decisions, making it likely to integrate wrongfully estimates that could turn into problems in a stage-gate process later stages.

\subsection{Knowledge maturity}

The concept of Knowledge maturity (KM) can "assist the identification and assessment of assumptions that are ingrained in the process." (Johansson 2009, p.45). In KM, the information helps to make an evaluation more accurate and sub-sequentially more effective, depending on both quantity and quality. $\mathrm{KM}$ is also important in order to agree on a common vision and goal, to properly convey risks and requirements among experts, including stakeholders (Johansson et al., 2011). Johansson et al. (2011) defined a list of seven requirements to be fulfilled by $\mathrm{KM}$ to be used as support for decision making. Those are listed as capabilities to support: boundary negotiation, tacit knowledge sharing, decision makers' learning, visualization, traceability, prioritization and pragmatic decision making. A KM scale has been proposed and applied in aerospace product development to assess the level of maturity of the knowledge based on the input, method and experience used during the decision gate (Johansson et al., 2011). The assessment scale does not claim to address all the KM requirements in a unique tool, it was generally constructed as an assistance to the stage-gate process and intended for gate review meetings. The scale is not a rigid system, rather a support to be implemented in evaluation routines. The KM scale uses a narrative scale to evaluate input, methods and experience. The scale defines KM as "inferior" when the content and rationale of the knowledge are characterised by instability and no formalised methods and procedures exist, as "acceptable" when content and rationale are more standardised and there is a greater extent of details compared to the "inferior" level, and as "excellent" when rationale and content are proven, there is a known confidence, and verified methods are used. Consequently, the scale has imprecise boundaries and is objective is not a precise assessment, rather it aims to create a "common denominator to debate" (Johansson et al., 2011) amongst evaluators and stakeholders.

\subsection{Conceptualizing certainty, uncertainty, ambiguity and risk}

Uncertainty is defined as the lack of knowledge and a void of necessary information where no clear understanding can be discerned (Ellsberg, 1961). However, uncertainty can be nuanced even further. Aleatory uncertainty pertains to the stochastic random variables and is representative of unknowns that differ each time we run the same experiment. For instance, even though parameters that influence effectiveness of a certain manufactured component are overall known, complicated vibrations of the individual parts of the component may produce small differences in effectiveness each time the product is tested. Thus, parameters can be assigned values, yet may contain variations that make exact prediction difficult (Raftery, 1996). Epistemic uncertainty concerns the subjective degrees of beliefs and the lack of knowledge, refers to things one could in principle know, but does not know at the particular point in time, or even ignore when making decisions practice. While aleatory uncertainty can be seen as the lack of knowledge within a certain context (but that it would be highly likely to be obtained if one further searched for it), epistemic uncertainty refers to not knowing about or trusting the problem structure, or that the context itself, is correct in the evaluation (Schrader et al., 1993). In other words, in situations characterized as uncertain, individuals have shared mental models, but typically lack information about 
how to configure variables or knowledge about functional relationship among variables. On the contrary, epistemic uncertainty refers to not knowing exactly what variables constitute a certain mental model of a problem and thereby also regard ambiguity. Consequently, in conditions where aleatory uncertainty exists, risk estimates are likely to be made with a margin of error. In conditions under epistemic uncertainty, variables may be added if looked for and then quantified, whereas under ambiguous conditions the mental model needs to be established, consequently making risk estimates difficult to be made. Not differentiating between the types of input for decision making may lead to either neglect or wrongful estimates and render potential dangers in the decision-making process.

Alexander (1975) and Schrader et al. (1993) defined a spectrum of situations concerning decision theory in risk and uncertainty which is complemented in order with to help understand the difference between Risk-Uncertainty-Ignorance, those are shown in Table 1.

Table 1. The relation between uncertainty, risk and ambiguity

\begin{tabular}{|l|c|c|c|c|}
\hline & \multicolumn{2}{|c|}{ Alexander (1975) } & \multicolumn{2}{c|}{ Schrader et al. (1993) } \\
\hline Spectrum & $\begin{array}{c}\text { Knowledge } \\
\text { situation }\end{array}$ & Spectrum & $\begin{array}{c}\text { Knowledge } \\
\text { situation }\end{array}$ & Spectrum \\
\hline $\begin{array}{l}\text { Aleatory } \\
\text { uncertainty }\end{array}$ & Certain & $\begin{array}{c}\text { Deterministic } \\
\text { Knowledge }\end{array}$ & $\begin{array}{c}\text { Low } \\
\text { Uncertainty }\end{array}$ & $\begin{array}{c}\text { Mental models include known variables, } \\
\text { values and functional relationships. }\end{array}$ \\
\cline { 2 - 5 } & Risk & $\begin{array}{c}\text { Complete probabilistic } \\
\text { knowledge }\end{array}$ & Uncertainty & $\begin{array}{c}\text { Mental models include known variables, } \\
\text { values, but functional relations are } \\
\text { unknown. }\end{array}$ \\
\hline $\begin{array}{l}\text { Epistemic } \\
\text { uncertainty }\end{array}$ & Uncertain & $\begin{array}{c}\text { Partial probabilistic } \\
\text { knowledge }\end{array}$ & Ambiguity & $\begin{array}{c}\text { Mental models include known variables, } \\
\text { values known or unknown, functional } \\
\text { relations are unknown. }\end{array}$ \\
\cline { 2 - 5 } & Ignorance & $\begin{array}{c}\text { No probabilistic } \\
\text { knowledge }\end{array}$ & $\begin{array}{c}\text { High } \\
\text { Ambiguity }\end{array}$ & $\begin{array}{c}\text { Variables and functional relationships } \\
\text { unknown. }\end{array}$ \\
\hline
\end{tabular}

The distinction between risk and uncertainty as complete probabilistic knowledge and partial probabilistic knowledge has been argued as "not helpful in the context of problem-solving." (Schrader et al., 1993, p. 79). This is because once uncertainty is used in an assessment, it is assumed that particular estimates have been implicitly used. Subjective judgements in decision making are rooted in expert opinions from respective domains, where a degree of belief is attached to how likely something is to occur. Yet gut feelings and intuitions are often used in industries (Johansson et al., 2014) to mimic reality when there is no additional information to be added, conservatively binding uncertainties in assumptions. This is where the need arises to create awareness about the consequences of how uncertainty and ambiguity are represented so that it can be grasped by the decision makers and relevant stakeholders (Zio and Pedroni, 2013).

\subsubsection{Decision making during ambiguous conditions}

At the onset of a decision-making process information is scarce and neither the mental models nor variables underpinning it are harmonized (cf. Ullman, 2003). These kinds of situations are particularly like to display a clustering of biased thinking. A chief concern is that decisions are likely to be based on "what first comes to mind". Availability bias occurs when people think that the ease of remembering certain events of facts indicates a high frequency of occurrence. This can arise irrespective of how many times the event has actually occurred (Tversky \& Kahneman, 1973; Reber, 2004). Thus, the bias is particularly pervasive for vivid or sensational events (Reber, 2004) and likely to distort thinking when people do not have the information or when they are not sufficiently motivated to systematically process or gather new information (Reber, 2004). The inherent time pressure of stage-gated decision making may contribute to low motivation to systematically process information since many ideas are typically favoured over few ideas. The combined lack of motivation and general lack of information during decision making provide ripe conditions for availability bias. The availability of (or lack thereof) information further distorts thinking since people tend to select options for which the probability of a 
favourable outcome is known, over an option for which the probability of a favourable outcome is unknown, a so-called ambiguity effect. As a consequence, such thinking may not only send decisionmakers off target as they identify input to decision making based on what first comes to mind, but also because they identify and favour known information over unknown information. In addition, people may spuriously detect relationships between variables, but sometimes this capability goes into overdrive such that decision-makers perceive relationships that do not actually exist. These falsely perceived relationships are known as illusory correlations (Fiedler, 2004).

Furthermore, the appeal to novelty is a fallacy in which one prematurely claims that an idea or proposal is correct or superior, exclusively because it is new and modern. This type of fallacy borderline biases under uncertainty conditions since some information regarding a decision needs to be known. In a controversy between status quo and new inventions, an appeal to novelty argument isn't in itself a valid argument. The fallacy may take two forms: overestimating the new and modern, prematurely and without investigation assuming it to be best-case, or underestimating status quo prematurely and without investigation assuming it to be worst-case. Investigation may prove these claims to be true, but it is a fallacy to prematurely conclude this only from the general claim that all novelty is good. The biases outlined above refers to conditions where the mental model of the problem space is unknown or not calibrated in a sufficient manner (ambiguous). There is very little available information about variables that represent the actual decision situation as well as little or none information about how to configure the variables making it representative of the decision situation. Suffering from either availability bias or illusory correlation would create conditions for decisions that face the risk of being completely off target outside of the domain of where the decision should have been made.

\subsubsection{Decision making during uncertain conditions}

In contrast to ambiguous situations, uncertain conditions imply that there are shared mental models of the problem, yet the configuration of the variables in the mental model is in a need of calibration. Thus, information is present, but it needs to be processed further. Consequently, this type of situation opens up for particular kinds of biases that regards a planning fallacy (Kahneman and Tersky, 1979). For instance, decision making regarding projects has been shown to display consistent over-estimation of success and benefits realisation, and under-estimation of cost and time resources. Consequently, such miscalibration has been shown to be present during the planning phase of projects and lead to over-runs and over-spends occurs during the project planning phase. There are also several reasons for this miscalibration. Anchoring is when decision-makers 'centre' their judgement on some initial reference point (anchor) when, for example, estimating a value. This illusion appears even when the anchor is clearly irrelevant to the decision at hand (Arvai et al., 2012) or an extreme value, and occurs even for experienced decision-makers (Mussweiler et al., 2004). Moreover, confirmation bias will potentially thwart the value assessment of parameters since there is a tendency to search for, interpret, favour, and recall information in a way that confirms one's pre-existing beliefs or hypotheses (Plous, 1993). People display this bias when they gather or remember information selectively, or when they interpret it in a biased way. The effect is stronger for emotionally charged issues and for deeply entrenched beliefs. Thus, it is quite likely that when decision parameters are identified under influence of ambiguous conditions, availability bias, illusory correlation or appeal to novelty individuals will make adjustments to such anchors. For instance, Kahneman and Tversky (2010) found that people chose certainty over moderate gains, but when certainty is about the same for two prospects and the gain slightly higher the choice differed significantly. These findings resonate with that subjects expect the worst in risk when prospects are gains (risk aversion), and expect the best in chance when prospects are losses (risk seeking) leading to both underweighting and overweighting of information. In this manner, a decision maker will side conservatively with assuming the worst and thus likely take the deal more certain of a risked gamble for gains (Ellsberg, 1961). Similarly, to the underweighting and overweighting of prospects individuals make judgments about how sure they are they are right. Another bias addresses this in terms of miscalibration between subjective confidence and objective confidence. Overconfidence has been called the most pervasive and potentially catastrophic of all biases (Plous, 1993). In other words, regardless of prior experience, individuals would assess themselves as more likely to be accurate than others, while in fact they statistically have an equal or less chance of doing so. While knowledge in a specific domain 
is argued to protect against inhibited decisions, Gervais and Odean (2001) found that overconfidence increased with experience as subjects accumulated more experience. Similarly, overconfident professionals sincerely believe they have the expertise and act as experts (Kahneman, 2011). Thus, overconfidence is not easily disregarded in a decision situation. Finally, although overconfidence may unfreeze team members from the status quo, other biases may cause team members to remain unwilling to change their behaviour. The status quo bias surfaces when disproportional weight is assigned to present conditions and when changes from this baseline are perceived as losses. Thus, a too restrictive view when assessing parameters, such as being underconfident may cause team members to prefer unchanged conditions.

\section{Research approach and methods}

The research presented in this paper was conducted following the framework of the Design Research Methodology (Blessing and Chakrabarti, 2009), in collaboration with an aerospace sub-system manufacturer. The aerospace industry suited the scope on high-consequence industry given the need of accuracy in decisions to guarantee the safety of aerospace vehicles to the furthest extent possible. The DRM methodology supported the early explorative parts of the research as the different steps led the work to be defined, clarifying topics, purpose, research plan and determining areas relevant to the research. The descriptive study initially focused on increasing the understanding of the findings from the research clarification, through a literature review. Later interviews were conducted with representatives from the company investigating how they perceive and work with uncertainty and ambiguity in relation to staged engineering decisions. The focus on perceptions of uncertain and ambiguous aspects of the decision-making process, rather than on objective measures, made interviews a suitable method to answer the exploratory nature of the research question. The prescriptive part of the followed the descriptive study by jointly using the theoretical (regarding biases and knowledge maturity) and empirical data to propose further considerations that are presented in the discussion section.

\subsection{Literature review}

To frame the literature review multiple ARC (Areas of Relevance and Contribution)-diagrams (Blessing and Chakrabarti, 2009) were initially drawn to represent many areas relating to evaluation, uncertainty, ambiguity and risk. A preliminary literature review was used in an early research clarification stage to identify and narrow down more specific research areas and keywords to use for the search of literature, eventually leading to the formulation of a single ARC diagram. Google Scholar, ISI Web of Science and Scopus were used as reference databases in literature search. The main keywords used were: Ambiguity, Risk and Uncertainty, Uncertainty and Risk Assessment, Uncertainty and Risk Analysis, Uncertainty and Decision Making, Decision Making, Decision Theory, Stage-Gate Process, Normative Theory Descriptive Theory, Knowledge Maturity. Keywords were phrased based on the areas of research defined in the ARC diagram. Further papers were found through cross-referencing citations from multiple papers. References that did not disclose relationships to other ARC-areas, or relevant information to the main topics in the ARC diagram, were disregarded.

\subsection{Data and analysis}

Six semi-structured interviews were conducted with company representatives who frequently engage in decision making in research and development. The interviews were recorded to enable transcriptions and analysis. The participants were handpicked by the partner company to represent different levels of experience and involvement in decision making, including project management and program management. This can introduce a bias as the company could try to safeguard against not to present themselves as incompetent, weak or unwilling to reveal biased thinking. However, the actual questions were not sent beforehand, as a mitigating tactic of strategic displays on behalf of the interviewees. As such, the questions drawn were directly related to factual details rather than personal performance when possible, and to counteract the fear of self-infliction from staff the participants were kept anonymous. Interviews were conducted in Swedish, but later, quotes were translated into English to be presented with the results. Additionally, feedback was given post-interview through excerpts from transcripts to 
confirm and nuance the contents. This iteration did not reveal any information that caused us to reconsider the interviewees' stories. Table 2 summarizes the data related to the interviews:

Table 2. Data about the semi-structured interviews

\begin{tabular}{|l|l|c|c|}
\hline Position in Company & Responsibility & $\begin{array}{l}\text { \# of } \\
\text { minutes }\end{array}$ & $\begin{array}{l}\text { \# coded } \\
\text { segments }\end{array}$ \\
\hline $\begin{array}{l}\text { Director and Head of Chief } \\
\text { Engineering }\end{array}$ & $\begin{array}{l}\text { Responsible for the group of Chief Engineers } \\
\text { making all of the decisions at a Program level. }\end{array}$ & 30 & 84 \\
\hline Chief Engineer & Program Lead & 31 & 62 \\
\hline Supply Management & Project Management & 30 & 49 \\
\hline Engineer in Charge & Project Management & 28 & 100 \\
\hline Process Manager & Program Lead & 35 & 42 \\
\hline $\begin{array}{l}\text { New Product Introduction } \\
\text { Lead - Design Manager }\end{array}$ & $\begin{array}{l}\text { Development Team Leader - } \\
\text { Project Management }\end{array}$ & 30 & 49 \\
\hline TOTAL: & & 184 & 386 \\
\hline
\end{tabular}

Coding was applied to the interviews to facilitate the analysis of the data. In Vivo Coding (King, 2008) was applied in order to more specifically portray "the terms used by actors in that field themselves". (Strauss, 1987 p. 33). Such coding was used because it facilitates relevant information to be captured in the phrases and acronyms commonly used by engineers in practice, as engineers would use terms more commonly associated to them, thus better suited for a research meant to build support for engineers. Descriptive Coding was only partially used to complement In Vivo Coding because, despite its practicality, it is typically more appropriate when a wide variety of data in different mediums is considered. To confirm the validity of the exploration of the research a Values Coding approach was integrated into the overall coding, and was applied to capture the interpersonal beliefs, values and attitudes towards the topics discussed (Saldaña, 2015). Thus, the coding procedure enabled to outline descriptions of processes and events as well as the interviewee's value statements about these particular events. Other approaches to coding were investigated but disregarded because they were judged as not fitting with the nature of the research. For instance, Provisional Coding needed an extensive preliminary setup of code that was not available; Hypothesis Coding would have first needed a well-defined hypothesis not available due to the explorative and descriptive purpose of the interview; Protocol Coding and Causation Coding were considered too open ended for the approach based on the semi-structural interview; Attribute Coding would have required multiple case studies and variable research whilst this research was limited to one company, Magnitude Coding was deemed to be more aligned to research that was purely rooted in social sciences, Holistic Coding was judged to be preferable when data from different collections and predefined batches are available. Other approaches to coding were mainly disregarded for their socially subjective objectives or their historical objective concerning the interviews such as Emotion Coding, Process Coding and Dramaturgical Coding. Furthermore, grammatical methods used to add mechanics to the approaches were also disregarded for their added complexity in a case of a wide variety of data and detail, which was deemed unfit for this research, with the exception of Simultaneous Coding (Miles et al., 2014). A Computer Assisted Qualitative Data Analysis Software was used to facilitate the process rendering a total of 386 coded segments (see Table 2), of which a few were selected for illustrative purposes responding to the question of how engineers in a highconsequence risk view uncertainty and ambiguity in engineering design decision-making.

\section{Results from the empirical study}

This section summarises the results from the empirical study describing the as-is situation at the partner company. Concerning how do engineers view uncertainty and ambiguity in engineering design decision making, the interview findings in aggregation highlighted that (I) engineers do not hold nuanced perceptions of, or differentiate between, types of information, such as between ambiguous and uncertain conditions and how these instances may influence different situations. This makes them susceptible to biases. (II) When considering problems engineers typically view uncertainty and risk interchangeably 
and deal with uncertainty (rather than ambiguity) through rather inert measures, typically awaiting more information or developing pre-conceived mitigation plans to circumvent the uncertainty. In cases of urgency where the engineers need to act, assumptions are built to give best estimates, typically without questioning mental models of problems. As stated in two interviews: "It can be like that often we will make assumptions, even together with the client. (...) who says "alright this seems reasonable, we'll go ahead with this" and "Normally we make several assumptions. We document these assumptions relatively well and underpin them to the best of our abilities". The excerpt highlight that there is an overall unclear role of suitable mental models and that they use multiple assumptions to create baselines for further decision-making. A pattern emerging from the coding of the interviews showed that the concept of uncertainty is often interchanged with the concept of risk. In general, engineers did not prove to distinguish clearly between uncertainty, ambiguity and risk (e.g. uncertainty and risk, "they're used synonymously, there's no difference that I see"; "I don't know that we differentiate between risk and uncertainties in relation to evaluations to any degree"), knowing the latter to be needed to be formalized in documentation to be used by the program lead to make decisions. Engineers tended to talk about uncertainty when referring to specific design issues (e.g. "I have experience with (...) thermal uncertainty"; "there is usually an uncertainty in the levels for the component loads"), while the term risk is preponderantly used when talking about decision making and documentation for the program lead. Thus, the interviewees support the view of uncertainty regards making adjustments to known mental models. Knowledge conditions are commonly evaluated by a risk assessment activity at a project group level by a multidisciplinary team of experts, as stated in one of the interviews: “...it is a team that's made up by of all sorts of disciplines, everything from manufacturing, purchasing, construction, aerothermo, mechanics of materials, material techies, all disciplines are actually involved...". The team formalizes uncertainty in terms of risk and communicated it to the program lead group without considering that the heterogeneity of group composition may pave way for use of several different mental models. It is later up to the program lead group to make decisions eventually following the recommendation by the project group. In this way, the decision makers do not directly deal with uncertainty which is already managed and formalized in a previous step in terms of risk. The perception of what is considered ambiguous and uncertain is therefore strongly biased by the methods and tools used by the project group to manage and translate such uncertainty. The empirical study showed that engineers are unlikely to differentiate between types of information, such as between ambiguous and uncertain conditions. A typical course of action for the engineers is to await more information or developing (often preconceived and underdeveloped) mitigation plans to circumvent problems. Furthermore, as a mitigating action, the engineers let a multidisciplinary team of experts to filter information to the program lead group, consequently raising the risk of causing decisions to be highly dependent on the tools used by the project group to manage and translate decision conditions, not considering heterogeneity of mental models that the group composition may bring. Thus, from the interviews, it emerged that the case company treats evaluations in decision making in a manner that would synergize stage-gated processes with the KM scale. The process to introduce the use of KM requires common denominators and traceability of inputs, models and expertise, which shall be documented during the design process. The case company already provided documentation throughout the course of the stage-gate process and also included stakeholders in the decision making. Although, an issue to be addressed concerns the definition of decision inputs, regarding differences between ambiguity, uncertainty and risk.

\section{Discussion of the findings}

Revisiting the research question "how do engineers in a high-consequence risk view uncertainty and ambiguity in engineering design decision making?" Decisions can be made accepting uncertainties, if the confidence on it is considered appropriate, given the condition that an uncertainty assessment exists. However, when decision input is unclear, biasing conditions emerge. For instance, being unclear about whether there is a shared mental model of the decision space among decision makers, raises the risk of the creation of reference points based on "what first comes to mind" (availability bias). If such bias affects the decision-making process, they may, in turn, contribute the use of faulty anchors, overconfidence, confirmation bias, which in turn leads to the preservation of unwillingness to change 
the current status-quo. Moreover, in order to calculate the risks one cannot ignore one's current state of knowledge. Calculating risks under ambiguous circumstances is directly misleading, calculating risks under uncertain conditions is possible given that the functional relationships among variables are known. Information should therefore be classified and assured to be uncertain, rather than ambiguous, before being assessed within a knowledge maturity scale in order to safeguard against biased thinking. A lack of information in cases of uncertainty means the assessment will wait until either more information enters the evaluation, or a mitigation plan which adjusts for heterogeneity of mental models is put into place. The decision makers would therefore need not only to categorize information, but also critically assess its value in terms of what reference points and mental models that are used in order to calibrate decision making. A knowledge maturity scale can support assessments under uncertainty, but it does not have features that define nor differentiate between ambiguity and uncertainty in assessments. To address this issue the categorization of knowledge situation and spectrum proposed by Alexander (1975) and Schrader, Riggs and Smith (1993) showed in Table 1, can be of good use. This is because understanding what kind of knowledge situation is present drives the decision to either collect new information or making a final decision converting uncertainty into risk. The biases that refers to ambiguity and uncertainty described in Section 3 need to be considered in an engineering design environment when taking decisions applying a knowledge maturity framework. Table 3 shows the hypothesized relationship between the biases and their effect on the KM requirements and on the narrative scale that is used for KM assessment. The table is derived from reflections about the empirical study linked to the literature findings in the area of uncertainty, ambiguity and risk. It does not encompass all the possible biases of decision making available in literature, rather a subset of them that were perceived to be relevant for the investigation. The aim of Table 3 is to highlight where problems can emerge when using a knowledge maturity scale in a gate meeting in presence of ambiguity and uncertainty. Such discussion is meant to suggest an area for further development and improvement of the knowledge maturity assessment in the form of tools and methods complementary to the KM scale.

Table 3. Problem emerging by using knowledge maturity in gate meetings in the presence of ambiguity and uncertainty

\begin{tabular}{|c|c|c|c|}
\hline $\begin{array}{l}\text { Type of } \\
\text { problem }\end{array}$ & $\begin{array}{c}\text { Biases in } \\
\text { Decision making } \\
\end{array}$ & $\begin{array}{l}\text { KM Requirements affected by the } \\
\text { biases }\end{array}$ & Consequences for the KM Scale \\
\hline \multirow[t]{3}{*}{$\begin{array}{l}\text { Ambiguity } \\
\text { condition } \\
\text { Referring to } \\
\text { initial gates } \\
\text { in staged } \\
\text { decision- } \\
\text { making }\end{array}$} & Availability bias & $\begin{array}{l}\text { Traceability: The definition of the } \\
\text { aspects influencing the design to be } \\
\text { traced has a high risk to be affected by } \\
\text { availability bias. } \\
\text { Prioritization: The decision to prioritize } \\
\text { an area has a high risk to be affected by } \\
\text { availability bias. }\end{array}$ & $\begin{array}{l}\text { The "Inferior" rate is driven by the } \\
\text { instability of content and rationale. } \\
\text { The risk is to choose a faulty } \\
\text { reference point of what is a "stable" } \\
\text { content and rationale. In other words, } \\
\text { team members need to be able to } \\
\text { account for where the idea comes } \\
\text { from. }\end{array}$ \\
\hline & Ambiguity effect & $\begin{array}{l}\text { Learning: the creation of what-if } \\
\text { scenario can lean towards an option for } \\
\text { which the probability of a favourable } \\
\text { outcome is known. } \\
\text { Pragmatic Decision Making: the need } \\
\text { to "move forward with manageable and } \\
\text { known risk" (Johansson et al., 2011) in } \\
\text { decision making introduces the } \\
\text { ambiguity effect bias. }\end{array}$ & $\begin{array}{l}\text { Taking a step back re-assessing and } \\
\text { re-classifying the information would } \\
\text { increase chances of discovering } \\
\text { shortcomings of reasoning as well as } \\
\text { increase chances for consensus } \\
\text { decisions. }\end{array}$ \\
\hline & $\begin{array}{l}\text { Illusory } \\
\text { correlation }\end{array}$ & $\begin{array}{l}\text { Prioritization: when "weighting" areas } \\
\text { and part of the whole in the presence of } \\
\text { high ambiguity, decision-makers can } \\
\text { introduce illusory correlation. }\end{array}$ & $\begin{array}{l}\text { To further scrutinize and critically } \\
\text { assess relationships between variables } \\
\text { with mental models by adding } \\
\text { additional variables to consider would } \\
\text { increase chances of finding spurious } \\
\text { correlations. }\end{array}$ \\
\hline
\end{tabular}




\begin{tabular}{|c|c|c|c|}
\hline & Appeal to novelty & $\begin{array}{l}\text { Tacit Knowledge sharing: Appeal to } \\
\text { novelty biases judgement based on gut } \\
\text { feeling and intuition driven by } \\
\text { experience. }\end{array}$ & $\begin{array}{l}\text { Introducing contrasting scenarios } \\
\text { would help to safeguard against } \\
\text { accepting exemplars as novel when } \\
\text { they really are not. }\end{array}$ \\
\hline \multirow[t]{5}{*}{$\begin{array}{l}\text { Uncertainty } \\
\text { Referring to } \\
\text { early but not } \\
\text { initial gates } \\
\text { in staged } \\
\text { decision- } \\
\text { making }\end{array}$} & Anchoring & $\begin{array}{l}\text { Wrongfully made incremental } \\
\text { adjustments relative to a reference } \\
\text { point. } \\
\text { Boundary Negotiation: about the } \\
\text { perception of the "value" of KM to be } \\
\text { used as a boundary object. } \\
\text { Visualization: KM requires to visualize } \\
\text { the level of maturity relative to the } \\
\text { required level. Anchoring bias is linked } \\
\text { to the initial definition of the required } \\
\text { level of KM. } \\
\text { Pragmatic Decision Making: Different } \\
\text { Go/no-go decisions can be taken based } \\
\text { on the initial reference point. }\end{array}$ & $\begin{array}{l}\text { The "acceptable" rate is based on a } \\
\text { subjective comparison of details with } \\
\text { "inferior" rate. The risk is of } \\
\text { judgement highly biased on the } \\
\text { referent point for "inferior". Letting } \\
\text { different groups make an assessment } \\
\text { of the same situation would help } \\
\text { detect anchors and potentially } \\
\text { mitigate the effect of it. }\end{array}$ \\
\hline & $\begin{array}{c}\text { Underweighting/ } \\
\text { Overweighting of } \\
\text { evidence }\end{array}$ & $\begin{array}{l}\text { The bias is similar to anchoring and } \\
\text { refers to the weighting of evidence in } \\
\text { assessments. } \\
\text { Tacit Knowledge Sharing: Experience } \\
\text { is overweighed giving a false sense of } \\
\text { certainty, or highly experienced } \\
\text { engineers understand better that they } \\
\text { don't know. }\end{array}$ & $\begin{array}{l}\text { There may be an overemphasis on } \\
\text { anecdotal information that could be } \\
\text { rooted in availability bias. Letting } \\
\text { independent assessors (both novice } \\
\text { and experts) make judgments about } \\
\text { acceptable intervals on parameters } \\
\text { would help to eradicate inexperienced } \\
\text { assessors overweighting and } \\
\text { experienced assessors to } \\
\text { underweighting. }\end{array}$ \\
\hline & Overconfidence & $\begin{array}{l}\text { Refers to the confidence in assessments. } \\
\text { Tacit Knowledge Sharing: } \\
\text { Inexperienced decision makers might } \\
\text { not perceive the uncertainty in their } \\
\text { knowledge. Expert decision makers } \\
\text { might be overconfident in their } \\
\text { previous experience. } \\
\text { Pragmatic Decision Making: the "need } \\
\text { to move forward" can create } \\
\text { overconfidence in what is perceived as } \\
\text { less uncertain }\end{array}$ & $\begin{array}{l}\text { The "Excellent" rate reflects the } \\
\text { perception of "known confidence" in } \\
\text { decision makers, inducing the high } \\
\text { risk of overconfident evaluation. }\end{array}$ \\
\hline & Confirmation bias & $\begin{array}{l}\text { Traceability: Look for confirming facts } \\
\text { in previous projects, even though } \\
\text { unrelated, can give a false sense of } \\
\text { knowledge maturity }\end{array}$ & $\begin{array}{l}\text { Making use of heterogeneity by } \\
\text { asking for contrasting evidence from } \\
\text { outsiders would help identify faulty } \\
\text { linking of evidence. }\end{array}$ \\
\hline & Status quo bias & $\begin{array}{l}\text { Prioritization and Pragmatic Decision } \\
\text { Making: Knowledge maturity is } \\
\text { perceived as higher if dealing with an } \\
\text { already set course of action. }\end{array}$ & $\begin{array}{l}\text { Unfreezing the return on investment } \\
\text { focus by promoting risk-seeking } \\
\text { behaviours. }\end{array}$ \\
\hline
\end{tabular}

The study also highlighted some limitations as well as important directions for future research. First of all, the empirical section does not directly evidence the presence of certain kinds of biases in the decision-making process of engineers. Yet, it showcases that considerations of uncertainty and ambiguity are worth to explore in more detail. Consequently, the small-scale empirical section of the study could be refined and extended considerably in order to more carefully find when and where these types of biases occur. This would be important since biases may be detrimental to decision making and it is important to know about their presence in order to mitigate them. Little research is done on how different kinds of biases may cluster, reduce or even amplify each other. The latter would be worth 
investigating since in this study availability bias is hypothesized to create defaults for decision making that are then worsened by anchoring adjustments. Yet, this assumption is in a need of empirical validation. Moreover, although having a negative influence on decision making, one should not disregard from the biases that may, in fact, produce positive outcomes if sufficient mitigating practices are developed for the decision-making process as a whole. For instance, availability bias may spur new ideas and illusory correlation may establish new baselines for previous unconsidered relationships. However, the positive side of biases may only be considered adequate if the KM-model holds sufficient mitigating practices to deal with the shortcomings later in the stage-gate model.

\section{Conclusions}

The study has discussed engineering design decision-making by analysing methods used to process uncertainties and ambiguities in early decision gates. An empirical study was conducted at a case company operating in aerospace product development to gain insights into how engineers view uncertainty, ambiguity and thereby risk in design choices. The study has discussed the concept of knowledge maturity in the light of the decision-making biases that occur in the presence of epistemic uncertainty and ambiguity. Knowledge maturity serves to better manage the lack of information by conveying confidence in the contextual source material for evaluation via a knowledge maturity scale. However, knowledge maturity is a topic in its infancy and needs further development and so the feature of discriminating between uncertain and ambiguous information is lacking. Consequences for omitting such a definition is discussed in terms of risk of potential biases. In the case of lack of specific knowledge, the assessment of knowledge maturity has yet to define a precise way to deal with ambiguities and uncertainties. The empirical study showed that often ambiguity and uncertainty are either neglected or simply observed until more information elucidates the issue.

\section{Acknowledgement}

The research leading to these results has received financial support by the Swedish Knowledge and Competence Development Foundation (Stiftelsen för kunskaps och kompetensutveckling) through the Model Driven Development and Decision Support research profile at Blekinge Institute of Technology.

\section{References}

Ajamian, G.M. and Koen, P.A. (2002), "Technology Stage-Gate ${ }^{\mathrm{TM}}$ : a structured process for managing high-risk new technology projects", In: Belliveau, P., Griffin, A. and Somermeyer, S., The PDMA Toolbook for new product development John Wiley and Sons, New York, pp. 267-298.

Alexander, E.R. (1975), “The limits of uncertainty: A note”, Theory and Decision, Vol. 6 No. 3, pp. 363-370. https://doi.org/10.1007/BF00136203

Arvai, J., Campbell-Arvai, V. and Steel, P. (2012), Systematic Review: Decision-making for sustainability. [online] Network for Business Sustainability. Available at: http://nbs.net/knowledge/business-case/decisionmaking/systematic-review/

Bell, D.E., Raiffa, H. and Tversky, A. (1988), Decision making: Descriptive, normative, and prescriptive interactions, Cambridge University Press. https://doi.org/10.1017/CBO9780511598951

Blessing, L.T.M. and Chakrabarti, A., (2009), DRM, a design research methodology, Springer Science \& Business Media. https://doi.org/10.1007/978-1-84882-587-1

Cooper, R.G., (2008), "The stage-gate idea-to-launch process-update, whatís new and NexGen systems”, Journal of Product Innovation Management, Vol. 25 No. 3, pp. 213-232. https://doi.org/10.1111/j.15405885.2008.00296.x

Ellsberg, D. (1961), "Risk, ambiguity, and the Savage axioms", The quarterly journal of economics, Vol. 75 No. 4, pp. 643-669. https://doi.org/doi.org/10.2307/1884324

Engwall, M., Kling, R. and Werr, A. (2005), "Models in action: how management models are interpreted in new product development", $R$ and D Management, Vol. 35 No. 4, pp. 427-439. https://doi.org/10.1111/j.14679310.2005.00399.x

Fiedler, K. (2004), "Illusory correlation", In: Pohl, R. (Ed.): Cognitive illusions: A handbook on fallacies and biases in thinking, judgment and memory, Psychology Press, New York, pp. 97-114.

Gervais, S. and Odean, T. (2001), "Learning to be overconfident", The Review of Financial Studies, Vol. 14 No. 1, pp. 1-27. https://doi.org/10.1093/rfs/14.1.1

Hansson, S.O. (2005), Decision theory: A brief introduction, Royal Institute of Technology. 
Johansson, C., Hicks, B., Larsson, A.C. and Bertoni, M. (2011), "Knowledge maturity as a means to support decision making during product-service systems development projects in the aerospace sector", Project Management Journal, Vol. 42 No. 2, pp. 32-50.

Kahneman, D. (2011), Thinking, fast and slow, Farrar, Straus and Giroux, New York.

Kahneman, D. and Tversky, A. (1979), "Intuition prediction: Biases and corrective procedures", Management Science, Vol. 12, pp. 313-327

Kahneman, D., Knetsch, J.L. and Thaler, R.H. (1991), “Anomalies: The endowment effect, loss aversion, and status quo bias", The journal of economic perspectives, Vol. 5 No. 1, pp. 193-206. https://doi.org/10.1257/jep.5.1.193

King, A. (2008), "In vivo coding”, In: Given, L.M. (Ed.): The SAGE encyclopedia of qualitative research methods, pp. 473-474.

Miles, M.B., Huberman, A.M. and Saldana, J. (2014), Qualitative data analysis: A method sourcebook, Sage Publications, CA, US.

Mussweiler, T., Englich, B. and Strack, F. (2004), “Anchoring effect”, In: Pohl, R. (Ed.): Cognitive illusions: A handbook on fallacies and biases in thinking, judgment and memory, pp. 183-200, Psychology Press, New York.

National Research Council (2011), "Risk Assessment and Uncertainty", In: Limiting Future Collision Risk to Spacecraft: An Assessment of NASA's Meteoroid and Orbital Debris Programs, The National Academic Press, Washington, DC, pp. 40-46.

Plous, S. (1993), The psychology of judgment and decision making, McGraw-Hill Book Company.

Raftery, J. (2003), Risk analysis in project management, Routledge.

Rakow, T. (2010), "Risk, uncertainty and prophet: The psychological insights of Frank H. Knight", Judgment and Decision Making, Vol. 5 No. 6, pp. 458-466.

Reber, R. (2004), “Availability”, In: Pohl, R. (Ed.), Cognitive illusions: A handbook on fallacies and biases in thinking, judgment and memory, pp. 147-163. New York: Psychology Press.

Saldaña, J. (2015), The coding manual for qualitative researchers, Sage.

Schrader, S., Riggs, W.M. and Smith, R.P. (1993), "Choice over uncertainty and ambiguity in technical problem solving”, Journal of Engineering and Technology Management, Vol. 10 No. 1-2, pp. 73-99. https://doi.org/10.1016/0923-4748(93)90059-R

Smidts, A. (1990), Decision making under risk. A study of models and measurement procedures with special reference to the farmer's marketing behaviour (No. 18), Agricultural University, Wageningen.

Strauss, A.L., (1987), Qualitative analysis for social scientists, Cambridge University Press. https://doi.org/10.1017/CBO9780511557842

Tversky, A. and Kahneman, D. (1973), "Availability: A heuristic for judging frequency and probability", Cognitive psychology, Vol. 5 No. 2, pp. 207-232. https://doi.org/10.1016/0010-0285(73)90033-9

Tversky, A. and Kahneman, D. (1986), "Rational choice and the framing of decisions", Journal of Business, Vol. 59 No. 4, pp. S251-S278. https://doi.org/10.1086/296365

Ullman, D.G. (2003), The Mechanical Design Process, McGraw-Hill, New York.

Zio, E. and Pedroni, N., (2013). Literature review of methods for representing uncertainty. FonCSI. Toulouse, 2013.

Dr.-Ing. Alessandro Bertoni, Assistant Professor / Senior Lecturer

Blekinge Institute of Technology, Mechanical Engineering

Campus Gräsvik, 37179 Karlskrona, Sweden

Email: alessandro.bertoni@bth.se 